\title{
Editorials
}

\section{Type 2 diabetes:}

\author{
prevention and cure?
}

General practice in the UK has been very successful in meeting the challenges raised by increasing prevalence of diabetes. Most diabetes is now managed in general practice and disease registers, evidencebased care, diabetes clinics, and diabetes trained practice nurses are now routine.

As a consequence of the obesity epidemic, and the ageing population, diabetes rates are rising, and diabetes can remain undiagnosed for many years. GPs have made progress in recent years in identifying previously undiagnosed cases. Recent population-based reports suggest that only $3 \%$ of men and $1 \%$ of women over 50 years have undiagnosed diabetes. ${ }^{1}$

\section{PREVENTION}

However, many more people are at high risk of developing diabetes $116 \%$ of people aged over 60 years have impaired fasting glucose), ${ }^{2}$ and detecting these people is important because it has been shown that type 2 diabetes can be prevented in a costeffective fashion in people at high risk by weight loss secondary to alteration in diet and exercise. ${ }^{3}$ There are major problems in translating this research success into everyday practice, chief among these are how to identify people with undiagnosed diabetes or at high risk; and how to intervene once they have been identified.

Screening for diabetes is currently not cost-effective, ${ }^{4}$ although focused case finding has been advocated for some time. The efficiency of looking for diabetes can be greatly improved by initial use of risk scores. Both the Leicester and the Cambridge risk scores can be run on routinely collected data in computerised databases. These scores identify who within the population is at high enough risk to warrant a blood test for diabetes.

But the question is how to get these blood tests done? The framework of the NHS Health Check Programme ${ }^{5}$ provided the perfect solution to this. The Vascular Screening Programme (VSP) comprises 5-yearly screening for all people aged 40-74 years from 2009. At these NHS Health Checks, each person will be invited for a standard assessment, with a blood test for cholesterol levels and lin some cases) glucose levels. This would lead to an individually tailored assessment outlining the level of vascular risk and appropriate action to take to reduce it.
Earlier this year NICE guidance effectively recommended that all white people over 40 years have a test for diabetes every 5 years and that people from ethnic minority groups have this regular testing from the age of 25 years as an addendum to the NHS Health Checks. ${ }^{6}$ This two-stage approach initially involves an assessment using a computer based validated risk assessment score (Leicester or Cambridge) of all persons over 40 years land those over 25 years in known high risk groups). The Leicester group, ${ }^{7}$ in this issue of the BJGP offers a practical scheme for doing this in a busy general practice, a process greatly simplified by the use of risk assessment scores, and measurement of $\mathrm{HbAlc}$ rather than fasting blood glucose tests. People identified as being in the top $50 \%$ of diabetes risk using a computer-based risk assessment tool, can be opportunistically offered a HbA1c test to identify those with diabetes and those at high risk who require intensive structured lifestyle intervention and annual $\mathrm{HbA} 1 \mathrm{c}$ monitoring.

The agreement that one $\mathrm{HbA} 1 \mathrm{c}$ result of $6.5 \%$ (48 mmol/l) or more with symptoms (or two without symptoms) is diagnostic of diabetes offers a step forward in detecting people who may have previously undiagnosed disease, as unlike measures of blood glucose the test does not require the patient to fast. ${ }^{8}$ The recommendation that results of between $6.0 \%$ and $6.4 \%$ (42-47 mmol/ml) denote high risk for type 2 diabetes is debated ${ }^{8}$ but can be similarly useful in identifying people at high risk of type 2 diabetes. Gholap et al ${ }^{7}$ also gives succinct advice on the correct use of the $\mathrm{HbA} 1 \mathrm{c}$ test and its results.

Finally the Gholap paper ${ }^{7}$ summarises in a very manageable form what actions should be taken at each level of risk. These largely consist of encouraging weight loss by lifestyle interventions and treating associated risk factors and clinical problems. Negative attitudes to the possibility of weight loss have been widespread in general practice. ${ }^{9}$ However evidence-based interventions are appearing that are feasible and effective in general practice. Following the Scottish Counterweight study's success with GP-based interventions to reduce weight by $5 \%$ in obese patients ${ }^{10}$ Lean and colleagues in this issue of the $B J G P^{11}$ report on the feasibility and results of a low-energyliquid-diet (833 kcal per day) treatment and maintenance programme for severe obesity. Ninety-one people participated, the intervention was delivered by practice nurses or dieticians, and at 1 year 68/91 (75\%) participants had an average weight loss of $12 \mathrm{~kg}$. Even with the limitations of their study design the results are encouraging.

So in theory a feasible plan is in place for identifying diabetes cases and diabetes risk and doing something about these things. Unfortunately the Vascular Screening Programme does not have the status of a Health Technology Appraisal and so funding its implementation is not mandatory. So far the Vascular Screening Programme has only been variably implemented by the primary care trusts (PCTs), ${ }^{12}$ and there is no systematic approach to monitor the outcomes. It is under the auspices of public health, which moves to local authorities in April 2013, and it is unclear what will happen to the scheme in that cash-strapped environment. The current approach looks sensible but the challenge will be implementation. Meanwhile there is a need for effective local interventions for patients, including psychological support.

\section{CURING DIABETES?}

There is increasing evidence that not only can type 2 diabetes be prevented but that it can be cured. We have known for decades that gastric by-pass surgery results in long term normalisation of blood glucose but most of these studies have been on people with BMls above $35 .{ }^{13}$ This has now been shown even with people who have only class I obesity, that is, a BMI of 30-35, with $88 \%$ of 66 people with diabetes at baseline remaining diabetes free after 6 years of follow-up. ${ }^{14}$ Now evidence is appearing that

\section{"There is increasing evidence that not only can type 2 diabetes be prevented but that it can be cured.}




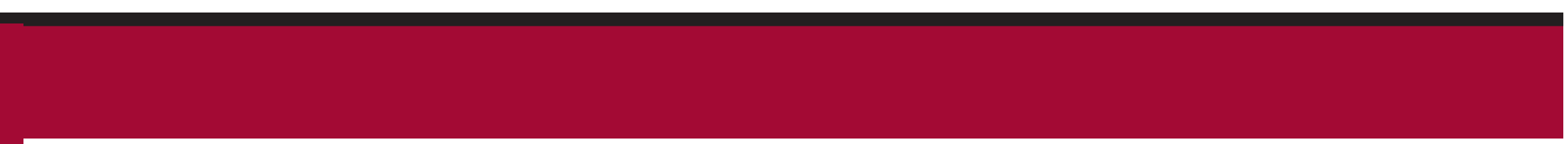

“... if a patient is prepared to lose $15-20 \%$ of their body weight and keep it off, there is a very good chance of their diabetes being cured ...

similar results can be obtained with very low calorie diets. The Counterpoint study has shown that in 10 of 11 people with diabetes an 8-week 600 kcal per day diet resulted in normalisation of glucose levels. After 12 weeks of normal diet, glucose tolerance was normal in four, impaired glucose tolerance in three, and diabetic but improved control in three. ${ }^{15}$ Both bariatric surgery and very low calorie diets produce rapid substantial weight loss with dramatic reduction of fat (triacylglycerol) stores in the pancreas and liver. The Counterpoint Study not only demonstrated very low calorie diets can produce weight losses similar to those of bariatric surgery, but offered an explanation of the anti-diabetic effect: reduction of triacylglycerol in the liver improves hepatic insulin sensitivity and reduction of triacylglycerol in the pancreas allows restoration of beta cell function. The upshot of these and similar studies is that if a patient is prepared to lose $15-20 \%$ of their body weight and keep it off, there is a very good chance of their diabetes being cured and that this seems to be related to the degree of weight loss rather than the duration of their diabetes. It may be true that many will not want to or be able to make such changes to their diet and lifestyle but initial responses to the Counterpoint study from the general population suggest that there is a health-motivated subset of the population who can reverse their diabetes completely and maintain long

\section{ADDRESS FOR CORRESPONDENCE}

\section{Mary Pierce}

Medical Research Council, Unit for Lifelong Health and Ageing, 33 Bedford Place, London, WC1B 5JU, UK

\section{E-mail: m.piercedanshd.mrc.ac.uk}

term normoglycaemia. Taylor suggests that at the time of diagnosis such healthmotivated individuals should be advised of this. If however they are unsuccessful in achieving substantial weight loss then the routine guidelines for type 2 diabetes should be rolled out. ${ }^{16}$

\section{CONCLUSION}

The Vascular Screening Programme with the diabetes addendum will improve the health of the population and commissioners should consider this as a priority for investment.

\section{Mary Pierce,}

GP and Clinical Epidemiologist, Medical Research Council Unit for Lifelong Health and Ageing,

London.

\section{Provenance}

Commissioned; not externally peer reviewed.

\section{Competing interests}

The author has declared no competing interests.

DOI: 10.3399/bjgp13X661002

\section{REFERENCES}

1. Pierce MB, Zaninotto P, Steel N, Mindell J. Undiagnosed diabetes-data from the English longitudinal study of ageing. Diabet Med 2009 26(7): 679-685.

2. Thomas MC, Walker MK, Emberson JR, et al Prevalence of undiagnosed Type 2 diabetes and impaired fasting glucose in older British men and women. Diabet Med 2005; 22(6): 789-793.

3. Herman WH, Hoerger TJ, Brandle M, and for the Diabetes Prevention Program Research Group. The Cost-Effectiveness of Lifestyle Modification or Metformin in Preventing Type 2 Diabetes in Adults with Impaired Glucose Tolerance. Ann Intern Med 2005; 142(5): 323-332.

4. Waugh N, Scotland G, McNamee P, et al Screening for type 2 diabetes: literature review and economic modelling. Health Technol Assess 2007; 11(17): $1-146$.

5. Department of Health. Putting prevention first. Vascular checks: risk assessment and management. London: DoH, 2008. http:// unw.dh.gov.uk/en/Publicationsandstatistics/ Publications/PublicationsPolicyAndGuidance/ DH_083822 (accessed 7 Jan 2013).

6. National Institute for Health and Clinical Excellence. Preventing type 2 diabetes -risk identification and interventions for people at high risk of diabetes. NICE public health guidance 38. London: NICE, 2012. http://mww.nice.org.uk/ nicemedia/live/13791/59951/59951.pdf laccessed 7 Jan 2013).

7. Gholap N, Davies MJ, Mostafa S, Khunti K. Diagnosing Type 2 diabetes and identifying high risk individuals using the new glycated haemoglobin (HbA1c) criteria. Br J Gen Pract 2013; DOI: 10.3399/bjgp13X663244.

8. World Health Organisation. Use of haemoglobin Alc as a diagnostic test for diabetes. Geneva: WHO, 2011. http://unw.who.int/diabetes/ publications/report-hba1c_2011.pdf laccessed 14 Jan 2013).

9. Hoppé R, Ogden J. Practice nurses' beliefs about obesity and weight related interventions in primary care. Int J Obes Relat Metab Disord 1997; 21(2): 141-146.

10. Nanchahal K, Townsend J, Letley L, et al. Weightmanagement interventions in primary care: a pilot randomised controlled trial. Br J Gen Pract 2009 . 59(562): e157-166.

11. Lean M, Brosnahan N, McLoone P, et al Feasibility and indicative results from a 12-month low-energy liquid diet treatment and maintenance programme for severe obesity. $\mathrm{Br} J$ Gen Pract 2013; DOI: 10.3399/bjgp13X663073.

12. Diabetes UK. 2012 NHS health check-let's get it right. http://www.diabetes.org.uk/Documents/ Reports/nhs-health-check-lets-get-it-right-0912. pdf laccessed 14 Jan 2013).

13. Buchwald H, Estok R, Fahrbach $\mathrm{K}$, et al. Weight and type 2 diabetes after bariatric surgery: systematic review and meta-analysis. Am J Med 2009; 122(3): 248-256.

14. Cohen RV, Pinheiro JC, Schiavon CA, et al. Effects of gastric bypass surgery in patients with type 2 diabetes and only mild obesity. Diabetes Care 2012; 35(7): 1420-1428.

15. Lim EL, Hollingsworth KG, Aribisala BS, et al. Reversal of type 2 diabetes: normalisation of beta cell function in association with decreased pancreas and liver triacylglycerol. Diabetologia 2011; 54(10): 2506-2514.

16. Taylor R. The 2012 Banting Lecture. Reversing the twin cycles of Type 2 diabetes. Diabet Med 2012; DOI: 10.1111/dme.12039. [Epub ahead of print]. 